\title{
Lidil
}

Revue de linguistique et de didactique des langues

$53 \mid 2016$

Phraséologie et genres de discours

\section{Louis-Jean Calvet, La Méditerranée : mer de nos langues}

CNRS éditions, 2016, $328 \mathrm{p}$.

\section{Marielle Rispail}

\section{(2) OpenEdition}

\section{Journals}

Édition électronique

URL : http://journals.openedition.org/lidil/4017

DOI : $10.4000 /$ lidil.4017

ISSN : 1960-6052

\section{Éditeur}

UGA Éditions/Université Grenoble Alpes

Édition imprimée

Date de publication : 30 mai 2016

Pagination : 210-211

ISBN : 978-2-84310-326-1

ISSN : 1146-6480

\section{Référence électronique}

Marielle Rispail, «Louis-Jean Calvet, La Méditerranée : mer de nos langues », Lidil [En ligne], 53 | 2016,

mis en ligne le 01 janvier 2017, consulté le 31 octobre 2020. URL : http://journals.openedition.org/lidil/ 4017 ; DOI : https://doi.org/10.4000/lidil.4017 
mouvement des derniers travaux de Blanchet, qui se réclament d'une sociolinguistique «d'intervention», non coupée de l'action sociale et de ses retombées. Il se présente en 5 parties dont les titres sont déjà en soi une démonstration : l'introduction est sous-titrée Les pratiques linguistiques, un domaine de discrimination largement ignoré, la partie II Voir les choses autrement..., la partie III Comment s'est déployée et se maintient la glottophobie?, la partie IV La glottophobie en pratique: étude d'exemples, la partie V Des pistes et des principes pour combattre la glottophobie. L'auteur y décortique les phénomènes de représentations, de manipulations, de domination et de complicité générale, dont se nourrissent les glottophobies, au profit de pouvoirs sociaux et politiques qui en tirent les ficelles. Nourris d'exemples et d'extraits de discours courants, les chapitres avancent vers des propositions à la fois collectives et individuelles pour penser et vivre une pluralité linguistique plus humaine, qui préfigurerait peut-être une société future plus humaine elle aussi. Car, écrit Blanchet, « un autre monde (linguistique) est possible», un monde où les langues, acceptées dans toute leur diversité, ne seraient plus prétexte à domination et sélection.

Rafraichissant en ces temps de poisseuse grisaille.

Marielle Rispail

CELEC, UJM Saint-Étienne

Louis-Jean Calvet, La Méditerranée : mer de nos langues, CNRS éditions, 2016, 328 p.

Louis-Jean Calvet a depuis des années entamé une recherche sur la circulation des langues dans le pourtour méditerranéen. Certain-e-s ont déjà pu profiter de quelques pépites de cette réflexion, lors de séminaires à l'université d'Aix-en-Provence ou lors de la conférence pour la remise de l'ouvrage qui lui a été dédié Pour la (socio) linguistique ${ }^{1}$, en 2010.

La voici à présent aboutie avec la sortie de son ouvrage La Méditerranée : mer de nos langues, somme de savoirs et mises en relation

1. M. Gasquet-Cyrus, A. Giacomi, Y. Touchard \& D. Véronique, Pour la (socio) linguistique (pour Louis-Jean Calvet), Paris, L'Harmattan, 2010, 328 p. 
éclairantes, aussi léchée que le titre et la couverture le laissent prévoir. L'auteur y invite à une navigation sur ce «continent liquide» entre terres et voyageurs, en se fondant sur une «approche sociolinguistique et géopolitique» qui prend «les langues, linguce nostrce, comme fil rouge de cette histoire». Mémoires de nos conquêtes, circulations et rencontres, les langues offrent un retour sur ce que nous sommes et avons été, lumières peut-être sur ce que nous serons. Étudier leurs emprunts, les glissements de sens, les écritures ou l'évolution de la toponymie revient à décrire les traces des échanges humains au sein de cette «mare nostrum», dont l'auteur dit qu'elle est le «laboratoire de l'humanité depuis plus de 3000 ans ».

Marielle Rispail CELEC, UJM Saint-Étienne 